\title{
PROTESTANTISMOS E HISTÓRIA: a propósito dos 500 anos da Reforma Protestante
}

No mês de outubro de 2017 foram realizadas, em diversas partes do mundo, celebrações alusivas aos 500 anos da Reforma Luterana, comumente chamada de Reforma Protestante. O centro das comemorações foi a pequena cidade alemã de Wittenberg, atualmente com pouco mais de 50 mil habitantes e que abriga a Igreja do Castelo de Wittenberg, local onde em 31 de outubro de 1517 o monge Martinho Lutero afixou suas 95 teses com críticas à Igreja Católica. Esse ato foi considerado como o desencadeador dos movimentos que provocaram a maior divisão institucional no interior do cristianismo romano.

Os movimentos contestadores e reformistas subsequentes a Lutero, tais como: o calvinista, o anglicano, os anabatistas, entre outros, provocaram profundas mudanças na vida religiosa na Europa e, posteriormente, em outras partes do mundo. Mais do que a crítica institucional, burocrática, clerical, os tempos posteriores a Lutero apontaram para uma nova posição religiosa do cristão para com o sagrado, o divino. Sem as intermediações dos agentes cultos e letrados, os fiéis passaram a ter acesso direto ao divino por meio da leitura devocional dos textos bíblicos. A tradução da Bíblia para o alemão pode ser considerado o ápice da quebra do monopólio do sagrado por parte da Igreja romana. E essa necessidade, esse imperativo para a leitura da Bíblia, marcou profundamente a identidade desses grupos religiosos e também direcionou a fundação e atuação das novas confissões eclesiásticas que investiam na alfabetização de seus novos membros. No Brasil, a partir do século XIX, algumas igrejas protestantes que por aqui chegaram por meio das missões adotaram a máxima "em cada igreja, uma escola".

Em terras brasileiras, os protestantes estão presentes, com regularidade, há pouco mais de 200 anos. Por aqui, é bastante perceptível a diversidade religiosa institucional, hoje frouxa, alargada, maleável - plástica. Diversidade que, por outro lado, configura um acirrado mercado religioso em torno dos bens de salvação no qual é possível encontrar de tudo: de igrejas voltadas para o público rock in roll, passando pelas igrejas para o público LGBTs às igrejas fundadas e dirigidas por povos indígenas. E para além das esferas institucionais, é cada vez mais intensa a formação de grupos religiosos virtuais, que reúnem evangélicos de diferentes confissões em grupos, comunidades, redes com ou sem o fim devocional. Ao lado de tudo isso, é crescente o número dos chamados "desigrejados", cristãos evangélicos que não se sentem representados por uma instituição específica, mas que "bebem água de toda a fonte" e continuam a professar o nome de evangélico nas molduras de identidades religiosas fugidias. 
Há também as festas. Das festas “juninas” sem São João e dos blocos de carnaval de Jesus às baladas e boates gospel. Mas, como nem tudo pode acabar em festa, nos últimos anos a arena política nacional tem sido a-balada com a atuação da Bancada Parlamentar Evangélica que em conjunto com deputados da Bancada Católica - nesse momento o anticatolicismo que tanto marcou uma identidade evangélica brasileira se dilui - atuam para implementar uma agenda conservadora no que diz respeito às temáticas como diversidade sexual e de gênero, abortamento, família, entre outros.

Tal como a própria temática, o Dossiê que ora apresentamos também é caracterizado pela diversidade. Diversidade de abordagens, de fontes documentais e bibliográficas, de sujeitos. O conjunto de textos permite ter contato com uma amplitude de experiências históricas brasileiras e de fora do país. O objetivo é que os leitores possam conhecer um pouco mais sobre o complexo mundo dos protestantismos e seus sujeitos, bem como das possibilidades de estudálos.

O artigo que abre a seção, intitulado "Do Evangelho segundo Lutero" é de autoria do historiador Adone Agnolin, e procura demonstrar como a historiografia protestante, sobretudo alemã, indicou a passagem da Idade Média para a Idade Moderna. Ao considerar que Lutero pregou as suas 95 teses à porta da igreja do castelo de Wittenberg, também se demonstra como a Reforma religiosa de Lutero coincidiu sobre o início da História Moderna. Busca apresentar com fidedignidade o que ocorreu no dia 31 de outubro de 1517 e em qual contexto Lutero se inseriu; da mesma forma, procura analisar o teor "reformador" da proposta contida nas teses originais de Lutero e, por último, almeja analisar como o seu gesto foi "revolucionário" até à época da Dieta de Worms em 1521.

O texto de Alonso S. Gonçalves, "Reforma e pluralismo religioso", apresenta uma leitura da Reforma perguntando se há uma contribuição da mesma para o que comumente conhecemos hoje como pluralismo religioso, com o intuito de demonstrar uma relação possível a ser explorada a partir das contribuições da Reforma para a temática e com o objetivo de contribuir com o diálogo inter-religioso.

O historiador André Szczawlinska nos brinda com o artigo sobre o avanço da Reforma Luterana no Norte Europeu, especificamente sobre a Livônia. Apresenta os processos que conduziram à instituição do Luteranismo na Confederação da Livônia, com o intento de demonstrar a necessidade de se considerar as Reformas religiosas do século XVI como eventos levados a cabo por agentes diversos, motivados por razões igualmente diversas, que vão de 
motivações espirituais e religiosas às de ordem política e econômica e acabam por convergir em estratégias de benefício mútuo.

"Das contribuições da teologia política da Reforma Protestante às declarações de direitos humanos" é o título do artigo de Givaldo Mauro de Matos, que analisa a proposição de que a Reforma Protestante representa um momento seminal do assentamento dos direitos individuais e, consequentemente, do espírito das declarações de direitos humanos modernos, tal como defendem os politólogos Georg Jellinek e Celso Lafer. O texto se desdobra em aferir o reconhecimento filosófico da relação entre o Cristianismo e o conceito de dignidade humana, o aprofundamento desde conceito promovido pela Reforma Protestante e a contribuição específica deste movimento para a naturalização dos conceitos fundamentais que deram origem às declarações de direitos humanos dos séculos XVIII e seguintes.

O artigo de autoria do historiador Vasni Almeida, intitulado "Fontes, teorias e métodos na escrita histórica sobre os protestantes e pentecostais no estado do Tocantins" apresenta estudos sobre igrejas evangélicas tradicionais e pentecostais no Tocantins, expondo as pluralidades de estratégias e representações religiosas verificadas no campo evangélico brasileiro, para o autor, "um campo ainda muito complexo e lacunar".

Ipojucan Dias apresenta a estreita relação entre o pastor metodista Justus Nelson, a Igreja Católica e a República, em Belém-Pará, e demonstra como esses agentes jamais se distanciaram de concepções político-religiosas quando o eixo versava a respeito do casamento e família. Guardadas as devidas proporções temporais, trata-se de um assunto que, nos dias atuais, tem provocado intensos debates e polêmicas.

O arqueólogo e antropólogo Rodrigo Pereira, a partir da documentação do Arquivo Histórico (AHI), do Ministério das Relações Exteriores (MRE), no Rio de Janeiro, referente às trocas de correspondências entre a Representação Brasileira em Hamburgo e em Berlim com a Secretária dos Negócios Estrangeiros do Império do Brasil, entre as décadas de 1840 e 1860, analisa a inserção do Luteranismo, especialmente os casos das Colônias de Santa Isabel (ES) e a de Petrópolis (RJ), e afirma que estas consistiram em uma ação estatal e não meramente uma epopeia de pastores voluntários, que visavam atender seus irmãos na fé.

Com o artigo “A 'Era Granbery': apontamentos sobre a inserção e consolidação do projeto educacional metodista em Juiz de Fora (1890-1930)", Everton Fernando Pimenta, analisa aspectos da atividade missionária realizada no Brasil por intermédio da Igreja Metodista Episcopal do Sul dos Estados Unidos, que intentava disseminar os ideais religiosos da denominação, os quais se entrelaçavam perfeitamente com certos elementos presentes na 
cultura norte americana. Recorrendo a categorias de Antonio Gramsci e da Nova História Cultural, o autor entende que as ações metodistas se pautaram pelo binômio educação e fé e analisa, assim, de que forma, por meio do Instituto Granbery, se deu a inserção e consolidação do projeto educacional metodista, ao ponto da instituição se configurar como o grande celeiro de seus intelectuais durante o período da "Era Granbery", contribuindo para que a cidade de Juiz de Fora viesse a ser considerada o "Vaticano do Metodismo brasileiro".

O tex to "Lidere como Jesus", de autoria da historiadora Karina Kosicki Bellotti, versa sobre os livros de liderança baseados na figura de Jesus Cristo e no modelo de liderança servidora, escritos por autores norte-americanos, com tradução para o público brasileiro. A abordagem segue a análise das relações entre religião e mídia, utilizando uma perspectiva histórica do desenvolvimento da literatura de liderança secular e religiosa ao longo do século XX. Analisa quais representações de Jesus Cristo são tomadas neste tipo de literatura, para demonstrar o modelo de liderança servidora em duas produções - a pioneira "The servant as leader", de Robert K. Greenleaf (1970), e "Lidere como Jesus" (2007), de Ken Blanchard e Phil Hodges.

Matheus Machado Vieira analisa as relações entre "Mídia, religião e globalização" e as representações da mulher no pentecostalismo digital a partir de uma perspectiva teóricometodológica que compreende as relações entre as expressões midiáticas da religiosidade pentecostal e os sentimentos na História. Os arcabouços que dão sustentação a essa análise são os fenômenos da globalização, do consumo e da propagação midiática: um cenário que atinge todas as formas de vida e expressões, entre elas a religião cristã. Por meio de duas lideranças pentecostais específicas, a pastora brasileira Sarah Sheeva e a escritora cristã estadunidense Stormie Omartian, o autor afirma que é possível compreender conceitos concernentes a identidade, representação e sentimentos no que diz respeito a um modelo de mulher, família e sexualidade.

Em “O fazer missionário, o fazer política: construção de relações para a atuação missionária na Terra Indígena Guarita nas décadas de 1960 a 1980”, Fernanda Caroline Cassador Costa, mostra a construção de relações locais e extra locais realizadas por missionários/atores religiosos ligados à Igreja Evangélica de Confissão Luterana no Brasil (IECLB) que atuaram na Missão Indígena Guarita entre as décadas de 1960 e 1980. E mostra ainda como essas relações exerceram influência nas práticas religiosas e missionárias da Igreja.

O historiador Leandro Seawright, no artigo "Etno-história-oral: a sobrevivência de uma indígena Kaingang e protestante à época da ditadura militar brasileira", analisa os 
fragmentos de uma narrativa de história oral concedida por Maria, uma indígena Kaingang de São Jerônimo da Serra, no norte do Paraná. Memórias de sofrimentos pessoais e familiares foram narradas e analisadas no presente texto, bem como as estratégias de negociações religiosas e vivências culturais que se apresentaram na abordagem.

E, para encerrarmos um Dossiê como este nada melhor do que uma citação: “"Nanderu é meu pastor e nada me faltará'. Pentecostalismos, invenções culturais e Povos Indígenas Guarani" é o título do artigo de autoria do cientista da religião Gustavo Soldati Reis. O objetivo do texto é analisar a presença de movimentos pentecostais e neopentecostais em aldeamentos indígenas, com presença étnica majoritariamente Guarani, na região Sul do Estado de Mato Grosso do Sul. Na análise empreendida prevalecem perspectivas antropológicas mais "funcionalistas" que focam a presença de missionamentos pentecostais nas aldeias como agências "lacunares", ou seja, só ocupam os espaços históricos e sociais onde a religião tradicional não encontra mais as condições necessárias para se reproduzir. Assim, destaca o autor, as igrejas e movimentos pentecostais assumem funções antes atribuídas à tradição de conhecimento nativo. Sem querer desconsiderar as importantes contribuições dessas análises, a perspectiva proposta procura outras direções. Uma dessas direções, com o auxílio dos estudos culturais, é perceber como os próprios indígenas apropriam-se do "universo simbólico" de produção de sentido posto pelas tradições pentecostais e "reinventam" suas experiências religiosas, em uma dialética entre táticas construídas e estratégias prescritas, tal como postulada por Michel de Certeau. Para Gustavo, a presença pentecostal nos aldeamentos radicaliza, por hipótese, o jogo dialético entre tradições e traduções religiosas, onde o protagonismo Guarani reinventa o seu jeito de ser religiosamente plural, ao mesmo tempo em que os pentecostalismos são, também, profundamente ressignificados.

Essa edição da Revista Fronteiras traz ainda cinco textos na seção de artigos livres. O primeiro, intitulado "Aqui todos somos migrantes o hijos de migrantes, tanto los brasileños como los paraguayos": memórias de migrantes brasileiros sobre a situação de colonização recente no distrito de Santa Rita, Departamento de Alto Paraná, Paraguai”, autoria de Andressa Szekut e Jorge Eremites de Oliveira, apresenta um estudo sobre a memória de brasileiros estabelecidos no Distrito de Santa Rita, Departamento de Alto Paraná, Paraguai, que migraram para o país vizinho durante um processo de colonização recente, iniciado nos anos 1970. Foi escrito a partir do levantamento e análise de fontes escritas e visuais, e de uma etnografia que privilegia a memória social e as representações de sujeitos históricos no contexto das redes de sociabilidade, constituídas no tempo e espaço. 
Alessandro Batistella, analisa "Fragmentos da história dos afro-descendentes em Passo Fundo/RS" e afirma que não se pode negligenciar a importância que determinados grupos étnicos subalternizados e deliberadamente esquecidos tiveram para a formação histórica da região norte do Rio Grande do Sul.

O texto "Reflexões sobre estudos de gênero no Plano Municipal de Educação de Campo Grande/MS e os diálogos com a história ensinada”, autoria de Jaqueline Ap. M. Zarbato e Vivina Dias Sol Queiroz tem por objetivo refletir sobre os debates que fundamentaram o Plano Municipal de Educação, em Campo Grande/MS (2015-2025), tendo em sua análise os 'embates' sobre a promulgação do documento, com as controvérsias sobre a inserção da abordagem e conceito de gênero.

"Entre desrespeito e reconhecimento: as comunidades quilombolas de São Roque e Rio do Meio (Ivaí, 1990-2016)”, autoria de Raphael Pagliarini, busca compreender o processo de constituição das comunidades quilombolas de São Roque e do Rio do Meio, situadas no município de Ivaí, Sudeste do Paraná, entre os anos de 1990 e 2015, a partir do diálogo com a teoria do reconhecimento social desenvolvida por Axel Honneth. Desta forma, problematiza as relações estabelecidas entre os negros e os demais grupos étnicos-sociais estabelecidos na região, entre os quais, alemães, poloneses e ucranianos.

O artigo de Rafael Amaro da Silva, "Plantas e mapas (o espaço desenhado): colonização da fronteira norte do império brasileiro através do projeto de fundação da Colônia Militar Pedro Segundo" aborda como o discurso oficial, apresentado pelos jornais e relatórios, e plantas da construção (projeto urbano), influenciou e retratou o cotidiano na colônia militar Pedro Segundo, considerando a importância de demarcar, vigiar e proteger a fronteira francobrasileira no Segundo Reinado.

Por fim, apresentamos a resenha do livro "Ritos da Oralidade: a tradição messiânica de protestantes no Regime Militar Brasileiro. Jundiaí: Paco Editorial, 2016”, feita pelo Natanael Francisco de Souza.

Assim, desejamos ótimas leituras e também agradecemos aos que atenderam ao convite e contribuíram com os textos para o Dossiê; bem como aos pareceristas, aos editores e aos autores da seção de artigos livres.

Carlos Barros Gonçalves (UFGD) Karina Kosicki Bellotti (UFPR) Leandro Seawright (UFGD, NEHO/USP)

(Organizadores do Dossiê) 